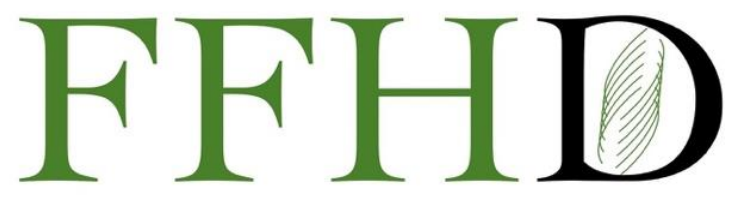

Functional Foods in Health and Disease

\title{
Safety of dietary undenatured type II collagen: a pilot open-label overdose clinical investigation
}

\author{
Yoshiaki Shiojima $^{1 *}$, Megumi Takahashi, ${ }^{1,2}$, Ryohei Takahashi, ${ }^{1,2}$, Hiroyoshi Moriyama ${ }^{1}$, Kazuo \\ Maruyama², Debasis Bagchi ${ }^{3}$, and Manashi Bagchi ${ }^{4}$ \\ ${ }^{1}$ Ryusendo Co., Ltd., R\&D, 1-5-3 Nishi-ikebukuro, Toshima-ku, Tokyo 171- 0021, Japan; ${ }^{2}$ Laboratory of Ultrasound \\ Theranostics, Faculty of Pharma Sciences, Teikyo University, 2-11-1 Kaga, Itabashi-ku, Tokyo 173-8605, Japan; ${ }^{3}$ College of \\ Pharmacy and Health Sciences, Texas Southern University, Houston, TX, USA; ${ }^{4}$ Dr. Herbs LLC, R\&D, Concord, CA, USA
}

*Corresponding Author: Yoshiaki Shiojima, Ryusendo Co., Ltd., 1-5-3 Nishi-ikebukuro, Toshima-ku, Tokyo 171-0021, Japan.

Submission Date: February 2nd, 2022; Acceptance Date: March 2nd, 2022; Publication Date: March 4th, 2022

Please cite this article as: Shiojima Y., Takahashi M., Takahashi R., Moriyama H., Maruyama K., Bagchi D., Bagchi M.. Safety of Dietary Undenatured Type II Collagen: A Pilot Open-Label Overdose Clinical Investigation. Functional Foods in Health and Disease 2022; 12(3):103-115. DOI: 10.31989/ffhd.v12i3.897

ABSTRACT

Background: In advancing age population worldwide, joint discomfort and poor locomotive functions are symptoms, which are often detected. Aggravation of such symptoms potentially develops into osteoarthritis (OA) as characterized by the loss of articular cartilage in the joints of the hand, spine, knee, foot, and hip. For joint health complications, selected functional foods are frequently supplemented orally to alleviate such symptoms. In Japan, Foods with Function Claims (FFC) regulatory system is now positioned within the framework of "so-called health foods" allowing to make functional claims such as brain health and weight control claims. Moreover, a wide variety of knee joint care FFC products are presently available in the marketplace and have attracted much attention of the elderly people, expecting improvements in joint locomotive functions such as walking, sitting, standing, and climbing the stairs for the quality of life (QOL). Supplementation of undenatured type II collagen powder (NEXT-II ${ }^{\oplus}$ ) in hard capsules has been clinically proven to improve such joint functions fulfilling part of the FFC rigorous guidelines, while ensuring adequate safety as foods is a crucial prerequisite for filing FFC product dossier.

Methods: Twenty-two healthy male and female volunteers (age $=20-74$ years) participated in this pilot open-label overdose clinical trial over a period of 4 consecutive weeks. All subjects were also monitored and assessed additional 2 
weeks after the completion of the NEXT-II ${ }^{\oplus}$ supplementation period as washout or supplement-free period. Subjects took a 10 -fold $(10-X)$ dose of NEXT-II (400 mg NEXT-II/day containing $32 \mathrm{mg}$ of undenatured type II collagen/day). Daily recommended dose of NEXT- $\|^{\oplus}$ is $40 \mathrm{mg} /$ day (containing $3.2 \mathrm{mg}$ of undenatured type II collagen/day) after breakfast. Physical health examination, hematological analysis, blood, biochemistry examination, and urinalysis were performed. All subjects completed the supplementation of NEXT-II for 4 weeks and had additional 2 weeks of washout or supplementfree period. All subjects recorded daily diaries.

Results: Results demonstrated no significant differences at 0 week (baseline), 2 weeks, and 4 weeks of NEXT-II ${ }^{\circledR}$ supplementation. Furthermore, no significant differences were observed even after 2 weeks of the washout period. No adverse events were observed.

Conclusions: Supplementation of 10 -fold dose of NEXT-II to the volunteers was well-tolerated and exhibited the broadspectrum safety without observing any adverse effects in healthy Japanese subjects.

Keywords: Undenatured type II collagen, NEXT-II', Safety, Overdose supplementation, Clinical study, Foods with Function Claims (FFC)

\section{Dietary Undenatured Type II collagen (NEXT-II $\left.{ }^{\circledR}\right)$ : An Overdose Clinical Investigation}

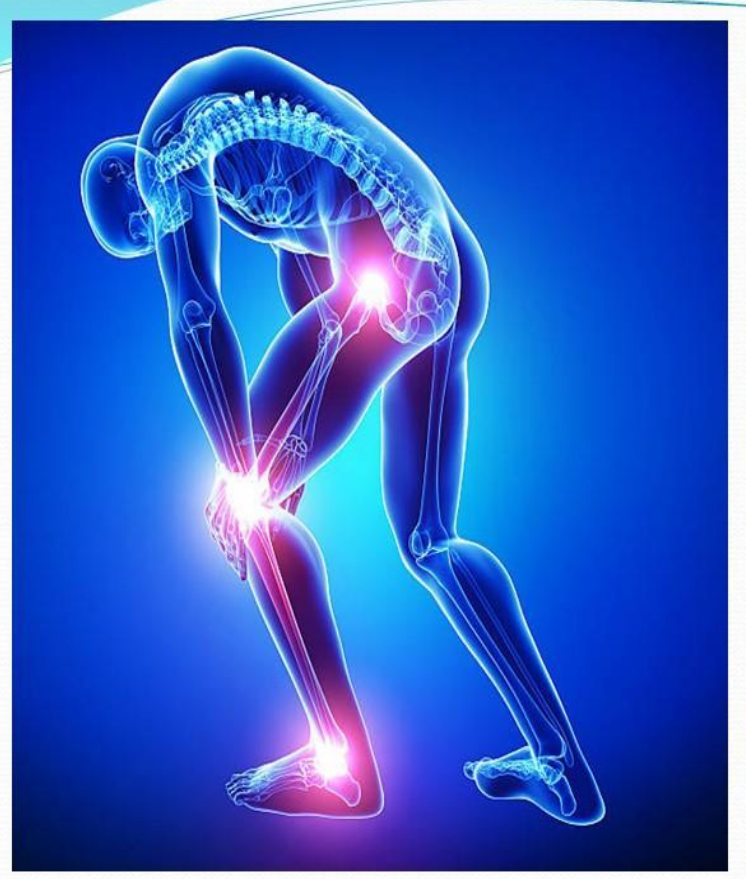

\section{Human Subjects A 10-Fold Dose}

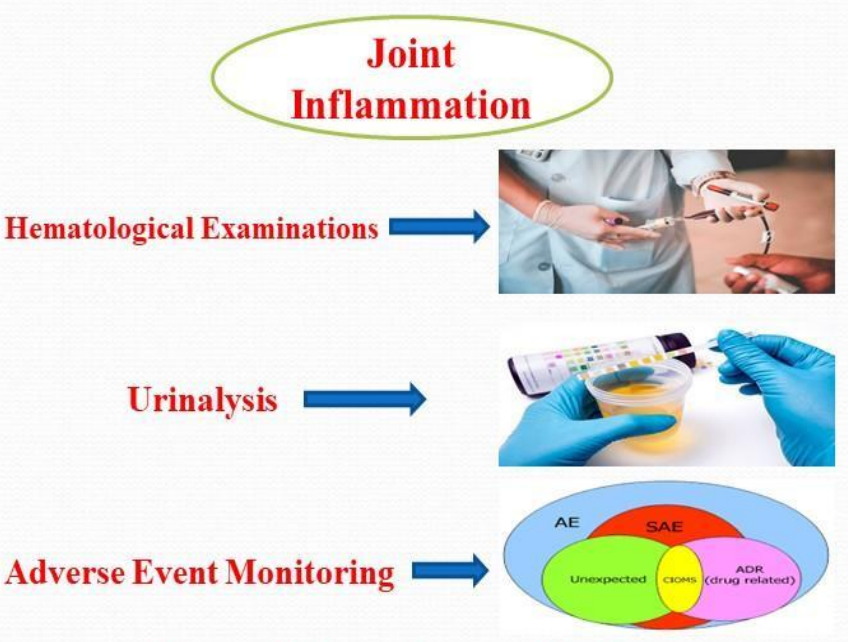

\section{Broad Spectrum Safety}

CFFC 2022. This is an Open Access article distributed under the terms of the Creative Commons Attribution 4.0 License (http://creativecommons.org/licenses/by/4.0)

\section{BACKGROUND}

Joint pain and discomfort, and poor locomotive functions are commonly observed in aging population and baby boomers worldwide. An increase of such symptoms potentially develops into osteoarthritis (OA), which is characterized by loss of articular cartilage in the joints of 
the hand, spine, knee, foot, and hip, all of which leads to the loss of synovial fluid in the joints, directing to an array of joint discomfort and pain, and restricts mobility. In recent years, occurrence of OA has become predominant in Japan, posing major socioeconomic concerns in Japan. Supplementation of selected functional foods and nutraceuticals, including glucosamine hydrochloride, $\mathrm{N}$ acetylglucosamine, undenatured type II collagen, hyaluronic acid, and turmeric extract have shown to be efficacious in attenuating joint pain, discomfort and enhancing mobility. These ingredients are sufficiently safe and exert potential benefits against joint discomfort and improving locomotive functions such as walking, sitting, standing, and climbing the stairs [1-7].

Among the functional food ingredients for joint health, undenatured type II collagen has been widely used for its proven beneficial effects on joint pain/discomfort and improving locomotive functions for many years [2-6]. Moreover, the ingredient is adequately safe with its common food origin and history of food use in the marketplace worldwide including Japan. It has also been demonstrated that undenatured type II collagen is highly safe for intake as evidenced by broad safety studies in animal models $[7,8]$. Multiple clinical studies have demonstrated their beneficial effects and efficacy in knee joint discomfort/pain and locomotive functions [3$6]$.

Our recent randomized clinical trial (RCT) demonstrated that undenatured type II collagen derived from chicken sternum cartilage (NEXT-II) significantly improved a wide array of discomfort/joint pain and difficulties in locomotive functions in human volunteers [6]. Most importantly, intake of a small amount of NEXT${ }^{\circ}{ }^{\circ}$ demonstrated to ameliorate knee joint discomfort and pain, while improving motor functions including flexibility and mobility.

In the present open-label overdose clinical study in male and female Japanese volunteers, we investigated to affirm the safety of a 10 -fold (10-X) NEXT-II overdose/day [400 mg capsules/day as $32 \mathrm{mg}$ of undenatured type II collagen/day] over a period of 4 weeks, followed by 2 weeks washout or supplement-free period. Physical health and well-being, hematological parameters, total blood chemistry, and urinalysis were performed. Adverse events were critically monitored.

\section{MATERIALS AND METHODS}

A pilot open-label 10 -fold overdose clinical study was conducted to ascertain the safety of undenatured type II collagen powder (NEXT-II) in hard capsules. NEXT-II capsules were administered to twenty-two male and female Japanese volunteers over a period of 4 consecutive weeks and additional 2 weeks of washout period. Physical health, hematological and blood biochemistry parameters as well as urinalysis were monitored during the study periods. All participants were requested to note all daily activities including diet and physical exercise, and adverse events, if any, in their daily diaries. The clinical trial protocol (protocol number: S2005) was approved (approval date: August 20, 2020) by the Institutional Review Board of Miura Clinic, Medical Corporation Kanonkai (Osaka-shi, Osaka, Japan) in accordance with the ethical standards established in the Helsinki Declaration (2013) and the ethical guidelines for epidemiological and clinical research of the Ministry of Education, Culture, Sports, Science and Technology, and the Ministry of Health, Labor and Welfare of Japan (2017). Furthermore, the study was pre-registered in UMIN clinical trials registry system (http://www.umin.ac.jp), which is in a public database (UMIN ID: 000041495). Written informed consent was obtained from all participants participated in the study. This study was conducted by a contract research organization, Oneness Support Co., Ltd. (Osaka-shi, Osaka, Japan), from August to October 2020 at the clinic.

Participants: Twenty-two subjects were selected based on the inclusion and exclusion criteria (Table 1), and twenty-one successfully completed the trial. 
Table 1. Inclusion and Exclusion Criteria

\section{Inclusion criteria}

- Healthy male and female volunteers (age: 20-74 years)

- $\quad$ Subjects with BMI less than $25 \mathrm{~kg} / \mathrm{m}^{2}$

- Subjects who received the details of the trial procedure explained by the chief investigator in advance, understood the procedure of the trial, and agreed to sign the written informed consent

\section{Exclusion criteria}

- Subjects who have history of liver, kidney, heart disease, cardiovascular, respiratory, endocrine, metabolic or neurological disorders, disturbance of consciousness, diabetes mellitus, or other disease and surgical procedure which might affect results of the overdose study

- Subjects who are presently undergoing therapeutic treatments

- Subjects who receive regular drug therapy or diet including health foods and supplements [including foods for specified health uses (FOSHU), foods with function claims (FFC), and foods with nutrient function claims FNFC)] which might affect results of the trial (except those subjects who can discontinue the drugs, health foods, and supplements intake at the time of obtaining informed consent)

- Subjects who have abnormal values in blood biochemistry

- Subjects who perform strenuous physical exercises or sports and undergo weight management

- Subjects who are presently participating or participated in the other clinical trials in the past 4 weeks or signed for other clinical trials

- Subjects who have allergic reactions related to the investigational product or any other foods or drugs

- Subjects who have previous experience of poor or health deterioration after giving a blood sample or who are anemic

- Subjects who had blood donations $\geq 200 \mathrm{~mL}$ in the month before the trial or plan to make blood donation $\geq 200 \mathrm{~mL}$ during the trial

- Subjects who are regular drinkers and smokers, who continue to drink and/or smoke the day before the trial and during the trial period

- Subjects who have extremely irregular lifestyles including erratic dietary patterns

- Subjects who are pregnant or breastfeeding women, or women who wish to be pregnant during the trial period

- Subjects who do not wish to provide their consent to the details of the trial explained to them in advance, meeting the criteria and providing a written informed consent were assigned trial subject identification numbers (preliminary test numbers) for the screening test.

- Subjects who were judged not appropriate by the chief investigator

Investigational product (IP): Undenatured type II collagen powder (NEXT-II'; Ryusendo Co., Ltd., Tokyo, Japan) used in this study was prepared from chicken sternum cartilage using demineralized water, followed by acid treatment, filtration, and freeze-drying. The purity of the resulting NEXT-II was measured using commercial 
ELISA kit and a standard product $(100 \mu \mathrm{g} / \mathrm{mL})$ of Chondrex, Inc. (Washington, USA) as previously mentioned in our study [6]. The NEXT-II (100 mg capsule containing $8.0 \mathrm{mg}$ undenatured type II collagen and crystalline cellulose was filled into dark brown hard capsules (HPMC, caramel color). Four capsules of the Investigational Product (IP) were taken once a day with water or warm water after breakfast, which was equivalent to 10 -fold (undenatured type II collagen $32 \mathrm{mg}$ $X 4$ capsules/day) of the recommended daily dose. The study materials were prepared in a good manufacturing practice (GMP)-certified facility on July 17, 2020.

Study design : This trial was a pilot open-label NEXT-II overdose study (10-fold dose) in 10 male and 11 female healthy Japanese volunteers (age range: 20-74 Y; mean age: $46.7 \pm 14.2$ Y) over a period of 4 consecutive weeks. Supplementation was performed over a period of 4 weeks, following which all subjects participated over a period of additional 2 weeks as washout or supplementfree period. Energy intake was not limited during the trial period and participants were instructed to maintain exercise levels as constant as possible. They submitted records of their diet and physical activity when they visited the hospital for tests taken at baseline ( 0 week) and at 2 and 4 weeks of taking NEXT-II ${ }^{\circledR}$ capsules. Details on participants' health conditions were obtained through medical interviews that the chief investigator conducted on the various test days. Information on adverse events was also obtained by the chief investigator from the clinical test results, medical interviews, and participants' records of diet and physical activity. Adverse events were recorded throughout the trial period and after the 2 weeks washout period.

Measurement of undenatured type II collagen (undenatured type II collagen): Undenatured type II collagen content in the NEXT-II ${ }^{\circledR}$ samples were determined using a commercial ELISA kit (Type II Collagen Detection Kit, Catalog \# 6018 of Chondrex, Inc., Washington, USA) and the accompanying reference standard (100 $\mu \mathrm{g} / \mathrm{mL})$ as previously described [6]. Undenatured type II collagen content per capsule was calculated from the average weight of one capsule. Undenatured type II collagen content was individually assessed by Ryusendo Co., Ltd. (Toshima-ku, Tokyo, Japan) and Teikyo University Faculty of Pharma Sciences (Itabashi-ku, Tokyo, Japan).

Measurement of physical health: Height and body weight were measured using a certified height scale, while body weight and body mass index (BMI) were assessed using a body composition meter (MS4900+201D; Moritoh Corporation, Ichinomiya-shi, Aichi, Japan); body temperature was measured with an electronic thermometer (C230; Terumo Corporation, Shibuya-ku, Tokyo, Japan); and blood pressure and pulse rate were measured twice with an automatic sphygmomanometer (digital sphygmomanometerHCR7106; OMRON HEALTHCARE Co., Ltd., Muko-shi, Kyoto, Japan).

Blood biochemistry and hematological parameters: Blood tests were conducted 4 weeks before the intake of NEXT-II ${ }^{\circledR}(0$ week) and after the intake period ( 2 weeks and 4 weeks) in the mornings on an empty stomach. Additionally, the parameters were monitored and evaluated at the washout or supplement-free period after 2 weeks of terminating the supplementation for 
observing any changes in the values of the examined parameters. The intake of food other than water was prohibited on the day prior to the blood collection. The parameters measured in the blood were alanine aminotransferase (AST), serum glutamic-oxaloacetic transaminase (SGOT), alanine transferase (ALT), serum glutamate pyruvate transaminase (SGPT), gamma glutamyl transpeptidase $\mathrm{\gamma}$-GTP, alkaline phosphatase $(A L P)$, creatine kinase $(C K)$, creatine phosphokinase $(\mathrm{CPK})$, creatinine $(\mathrm{Cr})$, uric acid (UA), blood urea nitrogen (BUN), total cholesterol (TC), HDL-cholesterol (HDL-cho), LDL-cholesterol (LDL-cho), triglyceride (TG), glucose (in fasting blood), lactate dydrogenase (LDH), total protein $(\mathrm{TP})$, sodium $(\mathrm{Na})$, potassium $(\mathrm{K})$, chloride $(\mathrm{Cl})$, calcium (Ca), inorganic phosphorus (IP), magnesium (Mg), iron (Fe), amylase (AMY), albumin (Alb), and HemoglobinA1c [HbA1c(NGSP: National Glycohemoglobin Standardization Program)].

The hematological examination parameters measured were white blood cell count (WBC), red blood cell count (RBC), hemoglobin level $(\mathrm{Hb})$, hematocrit value $(\mathrm{Ht})$, platelet count $(\mathrm{PLT})$, mean corpuscular volume (MCV), mean corpuscular hemoglobin $(\mathrm{MCH})$ and mean corpuscular hemoglobin concentration (MCHC). Blood was collected from the subjects at Miura Clinic, Medical Corporation Kanonkai (Osaka-shi, Osaka, Japan). All measurements were performed at LSI Medience Co., Ltd. (Toyonaka-shi, Osaka, Japan) using an automatic analyzer (BioMajesty $^{\text {TM }}$ JCA-BM8060 and JCA-BM9130: JEOL Ltd., Akishima-shi, Tokyo, Japan) and multi-item automatic blood cell counter (XN-9100: Sysmex Corporation, Kobeshi, Hyogo, Japan).
Urinalysis: Urinalysis was performed 4 weeks before the intake of NEXT-II ${ }^{\circledR}$ (0 week) and after the intake periods ( 2 weeks and 4 weeks). Additionally, the parameters were observed and evaluated at the washout period after 2 weeks of terminating the supplementation for monitoring any changes in the values of urinary parameters. The intake of food other than water was prohibited on the day before the blood collection. Urine was examined for urine specific gravity (USG), $\mathrm{pH}$, urinary protein (PRO), urinary glucose (GLU), urobilinogen (URO), occult blood reaction (BLD), urinary bilirubin (U-Bil), and ketone bodies (KET). The urine samples were collected at Miura Clinic, Medical Corporation Kanonkai (Osaka-shi, Osaka, Japan). All measurements were performed at LSI Medience Co., Ltd. (Toyonaka-shi, Osaka, Japan) using a fully automated urine analyzer (US-3500MS: Eiken Chemical Co., Ltd., Taito-ku, Tokyo, Japan).

\section{Record of diet and physical activity, and daily diary: The} subjects were urged not to change their diet or lifestyle during the study period. During the clinical trial, the test food intake, physical condition, diet, and physical activity were recorded in the subjects' diaries on a regular basis.

Statistical analysis: All tested values and changes $(\Delta)$ from baseline ( 0 week) are expressed as mean \pm standard deviation (SD). A paired t-test with Bonferroni correction was used in statistical analyses to examine significant differences between obtained values at baseline and 4 weeks. For significance level, two-tailed $5 \%$ was expressed for significant difference. Wilcoxon signed rank test with Bonferroni correction was also employed. 


\section{RESULTS}

Physical examinations: During the study one subject dropped out of 22 screened and enrolled participants, who were selected following the inclusion and exclusion criteria. One of the subjects dropped out from the study because of skin rash on day 4 of supplementation.
Although the rash disappeared after 4 days of the rash onset, the subject however decided to withdraw from the trial. As a result, 21 subjects were evaluated their physical health parameters at baseline ( 0 week) as shown in Table 2 and throughout the study periods at 2 weeks, 4 weeks and 2 weeks after the washout period.

Table 2. Baseline characteristics of the subjects

\begin{tabular}{|lc|}
\hline Parameters & \\
\hline $\mathrm{n}$ (Male / Female) & $21(10 / 11)$ \\
\hline Age (years) & $46.70 \pm 14.2$ \\
\hline Height (cm) & $164.63 \pm 8.74$ \\
\hline Body weight $(\mathrm{kg})$ & $56.22 \pm 10.65$ \\
\hline Body mass index $\left(\mathrm{kg} / \mathrm{m}^{2}\right)$ & $20.60 \pm 2.44$ \\
\hline Body temperature $\left({ }^{\circ} \mathrm{C}\right)$ & $36.52 \pm 0.36$ \\
\hline Systolic blood pressure $(\mathrm{mmHg})$ & $117.10 \pm 16.7$ \\
\hline Diastolic blood pressure $(\mathrm{mmHg})$ & $69.70 \pm 10.1$ \\
\hline Pulse (beats/min) & $82.0 \pm 14.7$ \\
\hline
\end{tabular}

Values represent the mean \pm SD.

The intake of NEXT-II ${ }^{\oplus}$ was $99.5 \pm 1.3 \%$ over a period of 4 weeks. In general, the numbers of male and female participants are almost even. During the study, one subject dropped out and thus, 21 subjects completed the study. The mean values of all parameters are within the reference (normal/healthy) range of average healthy Japanese population.

Contents of undenatured type II collagen in the treatment capsules: Undenatured type II collagen content in NEXT-II was $8.0 \pm 0.2 \%$ (mean $\pm \mathrm{SD}$ ). Undenatured type II collagen content in the NEXT-II capsules was $8.0 \pm 0.1 \mathrm{mg}$ (mean $\pm \mathrm{SD}$ ) per capsule (32 mg in 4 capsules per day).

Blood biochemistry and hematological examinations: During the trial period, both blood biochemistry and hematological parameters demonstrated some significant changes in the values of HDL-cho, glucose, $\mathrm{LDH}, \mathrm{Cl}, \mathrm{AMY}$ and MCV (Table 3). However, these values were well within the reference range, thus, supplementation of NEXT-II played no adverse role in affecting the health of the participants during the trial. Furthermore, some of the changes in these parameters continued to be noticed at the washout period, but the values are all well within the reference range. 
Table 3. Results of blood biochemical parameters, urinary USG and pH

\begin{tabular}{|c|c|c|c|c|c|c|}
\hline Parameters & Unit & Reference range & 0 weeks (Before) & 2 weeks & 4 weeks & $\begin{array}{l}\text { Follow-up } \\
2 \text { weeks }\end{array}$ \\
\hline AST (GOT) & $(U / L)$ & $10-40$ & $18.6 \pm 4.2$ & $19.4 \pm 4.7$ & $19.6 \pm 4.4$ & $18.5 \pm 5.3$ \\
\hline ALT (GPT) & $(U / L)$ & $5-40$ & $13.5 \pm 6.1$ & $15.7 \pm 7.2$ & $14.5 \pm 5.7$ & $15.3 \pm 7.6$ \\
\hline g-GTP & $(U / L)$ & $M: \leqq 70 ; F: \leqq 30$ & $20.5 \pm 11.5$ & $21.2 \pm 14.7$ & $20.0 \pm 12.2$ & $19.0 \pm 13.9$ \\
\hline ALP & $(U / L)$ & $115-359$ & $193.0 \pm 57.3$ & $205.0 \pm 68.1$ & $203.0 \pm 74.1$ & $198.5 \pm 66.6$ \\
\hline CK (CPK) & $(\mathrm{U} / \mathrm{L})$ & $M: 62-282 ; F: 45-163$ & $109.5 \pm 71.2$ & $111.8 \pm 74.7$ & $97.7 \pm 48.4$ & $108.8 \pm 62.0$ \\
\hline $\mathrm{Cr}$ & $(\mathrm{mg} / \mathrm{dL})$ & $\begin{array}{c}\mathrm{M}: \text { 0.61-1.04; F: } \\
0.47-0.79\end{array}$ & $0.712 \pm 0.141$ & $0.716 \pm 0.141$ & $0.717 \pm 0.140$ & $0.732 \pm 0.152$ \\
\hline T-Bil & (mg/dL) & $0.2-1.2$ & $0.89 \pm 0.27$ & $0.89 \pm 0.30$ & $0.92 \pm 0.31$ & $0.88 \pm 0.29$ \\
\hline UA & $(\mathrm{mg} / \mathrm{dL})$ & $\begin{array}{l}\text { M: } 3.7-7.0 \\
\text { F: } 2.5-7.0\end{array}$ & $4.50 \pm 0.98$ & $4.45 \pm 0.92$ & $4.49 \pm 0.99$ & $4.54 \pm 1.11$ \\
\hline BUN & (mg/dL) & $8.0-22.0$ & $13.54 \pm 3.10$ & $13.25 \pm 3.31$ & $13.05 \pm 2.28$ & $14.18 \pm 3.30$ \\
\hline TC & (mg/dL) & $150-219$ & $199.8 \pm 31.8$ & $204.0 \pm 31.7$ & $205.9 \pm 28.7$ & $200.4 \pm 31.5$ \\
\hline HDL-cho & $(\mathrm{mg} / \mathrm{dL})$ & $\begin{array}{l}\text { M: } 40 \text { - 86; } \\
F: 40 \text { - } 96\end{array}$ & $66.7 \pm 11.7$ & $70.3 \pm 15.3^{*}$ & $70.2 \pm 13.3$ & $69.7 \pm 15.0$ \\
\hline LDL-cho & (mg/dL) & $70-139$ & $117.6 \pm 25.0$ & $119.2 \pm 22.7$ & $122.2 \pm 22.0$ & $118.3 \pm 22.4$ \\
\hline TG & (mg/dL) & $50-149$ & $69.3 \pm 21.0$ & $79.0 \pm 39.8$ & $79.3 \pm 39.1$ & $76.9 \pm 40.1$ \\
\hline Glucose & (mg/dL) & $70-109$ & $88.7 \pm 7.4$ & $85.7 \pm 8.4^{*}$ & $85.4 \pm 7.4^{*}$ & $85.5 \pm 6.4^{*}$ \\
\hline LDH & $(U / L)$ & $115-245$ & $185.4 \pm 26.5$ & $185.5 \pm 24.8$ & $176.4 \pm 24.6^{*}$ & $166.0 \pm 28.5^{*}$ \\
\hline TP & (g/dL) & $6.7-8.3$ & $7.36 \pm 0.31$ & $7.30 \pm 0.35$ & $7.30 \pm 0.36$ & $7.10 \pm 0.36^{*}$ \\
\hline $\mathrm{Na}$ & $(\mathrm{mEq} / \mathrm{dL})$ & $136-147$ & $141.5 \pm 1.6$ & $141.4 \pm 1.4$ & $141.1 \pm 1.8$ & $140.2 \pm 1.6^{*}$ \\
\hline K & $(\mathrm{mEq} / \mathrm{dL})$ & $3.6-5.0$ & $4.02 \pm 0.29$ & $4.02 \pm 0.24$ & $4.08 \pm 0.24$ & $4.07 \pm 0.26$ \\
\hline $\mathrm{Cl}$ & $(\mathrm{mEq} / \mathrm{dL})$ & $98-109$ & $104.6 \pm 1.8$ & $103.5 \pm 1.7^{*}$ & $104.9 \pm 2.3$ & $103.7 \pm 1.7$ \\
\hline $\mathrm{Ca}$ & (mg/dL) & $8.5-10.2$ & $9.30 \pm 0.32$ & $9.24 \pm 0.27$ & $9.25 \pm 0.30$ & $9.22 \pm 0.28$ \\
\hline IP & (mg/dL) & $2.4-4.3$ & $3.34 \pm 0.52$ & $3.53 \pm 0.48$ & $3.47 \pm 0.47$ & $3.50 \pm 0.40$ \\
\hline MG & (mg/dL) & $1.8-2.4$ & $2.10 \pm 0.14$ & $2.16 \pm 0.11$ & $2.14 \pm 0.10$ & $2.16 \pm 0.13^{*}$ \\
\hline $\mathrm{Fe}$ & $(\mathrm{mg} / \mathrm{dL})$ & $\begin{array}{c}M: 54 \text { - 200; } \\
F: 48 \text { - } 154\end{array}$ & $100.9 \pm 28.4$ & $106.7 \pm 36.7$ & $109.1 \pm 31.3$ & $102.2 \pm 37.0$ \\
\hline AMY & $(U / L)$ & $37-125$ & $82.9 \pm 21.6$ & $94.2 \pm 27.5^{*}$ & $91.6 \pm 22.8^{*}$ & $89.9 \pm 21.4^{*}$ \\
\hline Alb & (g/dL) & $3.8-5.2$ & $4.49 \pm 0.25$ & $4.43 \pm 0.25$ & $4.55 \pm 0.28$ & $4.40 \pm 0.26$ \\
\hline HbA1c (NGSP) & (\%) & $4.6-6.2$ & $5.36 \pm 0.18$ & - & - & - \\
\hline WBC & $(/ \mathrm{ml})$ & $\begin{array}{c}M: 3900-9800 ; \mathrm{F}: \\
\quad 3500-9100\end{array}$ & $5404.8 \pm 1097.9$ & $\begin{array}{c}5295.2 \pm \\
1234.3\end{array}$ & $5500.0 \pm 1105.0$ & $5119.0 \pm 1061.9$ \\
\hline RBC & $\left(\times 10^{4} / \mathrm{ml}\right)$ & $\begin{aligned} M: 427 & -570 ; F: 376 \\
& -500\end{aligned}$ & $455.7 \pm 44.8$ & $454.4 \pm 43.1$ & $457.0 \pm 42.7$ & $453.4 \pm 46.1$ \\
\hline $\mathrm{Hb}$ & (g/dL) & $\begin{array}{c}M: 13.5-17.6 ; \mathrm{F}: \\
\quad 11.3-15.2\end{array}$ & $14.06 \pm 1.52$ & $14.01 \pm 1.33$ & $14.01 \pm 1.44$ & $13.95 \pm 1.48$ \\
\hline $\mathrm{Ht}$ & (\%) & $\begin{array}{c}\mathrm{M}: 39.8-51.8 ; \mathrm{F}: \\
\quad 33.4-44.9\end{array}$ & $44.15 \pm 4.03$ & $44.28 \pm 3.81$ & $43.81 \pm 4.08$ & $43.53 \pm 4.04$ \\
\hline PLT & $\left(\times 10^{4} / \mathrm{ml}\right)$ & $\begin{array}{c}\mathrm{M}: 13.1-36.2 ; \mathrm{F}: \\
13.0-36.9\end{array}$ & $26.87 \pm 5.14$ & $26.67 \pm 4.94$ & $27.00 \pm 5.30$ & $26.54 \pm 4.96$ \\
\hline MCV & $(\mathrm{fL})$ & $\begin{array}{c}M: 82.7-101.6 ; \mathrm{F}: \\
\quad 79.0-100.0\end{array}$ & $97.2 \pm 5.3$ & $97.7 \pm 5.6$ & $96.0 \pm 5.6^{*}$ & $96.3 \pm 5.2 *$ \\
\hline $\mathrm{MCH}$ & (pg) & $\begin{array}{c}M: 28.0-34.6 ; \mathrm{F}: \\
26.3-34.3\end{array}$ & $30.89 \pm 1.95$ & $30.91 \pm 2.12$ & $30.70 \pm 1.96$ & $30.82 \pm 1.91$ \\
\hline $\mathrm{MCHC}$ & (\%) & $\begin{array}{c}M: 31.6-36.6 ; \mathrm{F}: \\
\quad 30.7-36.6\end{array}$ & $31.81 \pm 1.04$ & $31.63 \pm 0.72$ & $31.97 \pm 0.82$ & $32.03 \pm 0.83$ \\
\hline USG & & $1.005-1.030$ & $1.0231 \pm 0.0080$ & $\begin{array}{l}1.0200 \pm \\
0.0075\end{array}$ & $1.0202 \pm 0.0081$ & $1.0196 \pm 0.0066$ \\
\hline $\mathrm{pH}$ & & $5.0-7.5$ & $5.93 \pm 0.75$ & $5.79 \pm 0.78$ & $6.10 \pm 0.78$ & $6.12 \pm 0.69$ \\
\hline
\end{tabular}

$\mathrm{M}=$ Male, $\mathbf{F}=$ Female; Values represent the mean $\pm \mathrm{SD} ; *$; $\mathbf{p}<0.05$ vs before $(0$ weeks $)$. 
Urinalysis: There were no significant qualitative changes in all parameters except that one subject showed " + " at 0 week (baseline) and one subject showed at " \pm " at 2 weeks in BLD, while two subjects showed " \pm " and "-" at 2 weeks (Table 4). At 4 weeks, all subjects found to be "-". The results of the washout period implied that the NEXT${ }{ }^{\circ}$ supplementation might not be related to the detection of BLD. For example, such results could be attributed to menstruation. Although we noticed one subject with " + " in KET at 2 weeks, the subject found to be normal at week 4 and at the washout period after 2 weeks of the termination of supplementation. These changes therefore are considered not due to effects of the NEXT$I^{\circ}$ supplementation.

Table 4. Results of urinary parameter

\begin{tabular}{|c|c|c|c|c|c|c|c|c|c|c|c|c|c|}
\hline \multirow[t]{2}{*}{ Parameters } & \multirow[t]{2}{*}{$\begin{array}{l}\text { Reference } \\
\text { range }\end{array}$} & \multicolumn{3}{|c|}{0 weeks (Before) } & \multicolumn{3}{|c|}{2 weeks } & \multicolumn{3}{|c|}{4 weeks } & \multicolumn{3}{|c|}{$\begin{array}{c}\text { Follow-up } 2 \\
\text { weeks }\end{array}$} \\
\hline & & - & \pm & + & - & \pm & + & - & \pm & + & - & \pm & + \\
\hline PRO & - & 20 & 1 & 0 & 21 & 0 & 0 & 21 & 0 & 0 & 19 & 0 & 2 \\
\hline GLU & - & 21 & 0 & 0 & 21 & 0 & 0 & 21 & 0 & 0 & 21 & 0 & 0 \\
\hline URO & \pm & 0 & 21 & 0 & 0 & 21 & 0 & 0 & 21 & 0 & 0 & 21 & 0 \\
\hline BLD & - & 19 & 1 & 1 & 17 & 2 & 2 & 21 & 0 & 0 & 16 & 2 & 3 \\
\hline U-BIL & - & 21 & 0 & 0 & 21 & 0 & 0 & 21 & 0 & 0 & 21 & 0 & 0 \\
\hline KET & - & 21 & 0 & 0 & 20 & 0 & 1 & 21 & 0 & 0 & 21 & 0 & 0 \\
\hline
\end{tabular}

$\mathrm{PRO}=$ Urinary protein; $\mathrm{GLU}=$ Urinary glucose; URO = Urobilinogen; $\mathrm{BLD}=$ Occult blood reaction; U $-\mathrm{BIL}=$ Urinary bilirubin; KET $=$ Ketone bodies

\section{Measurement during 4 weeks trial period and after 2} weeks of the washout period: Table 5 exhibits changes in the values of physical parameters at 0 week (baseline), 2 weeks, 4 weeks, and washout after 2 weeks of completing the trial. We observed no significant changes in values in the parameters over the trial period and also during the period of 2 weeks washout.

Table 5. Results of physical measurements and physical examination values.

\begin{tabular}{|c|c|c|c|c|}
\hline Parameters & 0 weeks (Before) & 2 weeks & 4 weeks & Follow-up 2 weeks \\
\hline Height $(\mathrm{cm})$ & $164.63 \pm 8.74$ & - & - & - \\
\hline Body weight (kg) & $56.22 \pm 10.65$ & $56.02 \pm 10.58$ & $56.10 \pm 10.71$ & $56.46 \pm 10.54$ \\
\hline Body mass index $\left(\mathrm{kg} / \mathrm{m}^{2}\right)$ & $20.60 \pm 2.44$ & $20.52 \pm 2.39$ & $20.55 \pm 2.46$ & $20.69 \pm 2.38$ \\
\hline Body temperature $\left({ }^{\circ} \mathrm{C}\right)$ & $36.52 \pm 0.36$ & $36.60 \pm 0.36$ & $36.45 \pm 0.36$ & $36.41 \pm 0.38$ \\
\hline Systolic blood pressure (mmHg) & $117.1 \pm 16.7$ & $117.3 \pm 17.1$ & $114.1 \pm 15.8$ & $121.7 \pm 15.7$ \\
\hline $\begin{array}{l}\text { Diastolic blood pressure } \\
(\mathrm{mmHg})\end{array}$ & $69.7 \pm 10.1$ & $72.1 \pm 10.3$ & $69.6 \pm 10.5$ & $69.6 \pm 11.2$ \\
\hline Pulse (beats/min) & $82.0 \pm 14.7$ & $79.0 \pm 15.3$ & $78.8 \pm 11.7$ & $78.5 \pm 11.5$ \\
\hline
\end{tabular}


Adverse event monitoring: No significant adverse side effects were reported. Throughout the study period, 5 mild adverse events occurred in 4 subjects (headache: 1 case, rash: 1 case, malaise: 1 case, fever: 1 case, menstrual pain: 1 case). The principal investigator (study physician) concluded that these events (cases) have no relevance to the supplementation of NEXT-II ${ }^{\oplus}$ capsules.

\section{DISCUSSION}

An open-label overdose clinical test using supplements might be unique to the function and health food regulatory system in Japan. Foods such as meat, vegetables and fruits are taken in our daily diets for nourishment and maintain healthy populations. Selected foods contain functional nutrients, exerting a wide range of health benefits. These functional ingredients are mostly extracted by solvents such as ethanol and/or water and concentrated extracts for supplements.

In Japan, clinically evidenced function and health foods with claims could be classified into FOSHU and Foods with Function Claims (FFC), which clearly differentiated from the positioning of "foods" or "socalled health foods". FOSHU has been well-recognized as "functional foods" in around 2000 accepting dosage forms such as capsules and tablets, which significantly contributed to the increase in health foods market size [9]. Furthermore, the FFC regulatory system was introduced in 2015 to provide scientifically evidenced products to consumers, assuring safety and efficacy of the FFC products based on filed dossiers by sellers to the Consumer Affairs Agency (CAA) [10]. Because FOSHU requires the government approval, FFC is allowed to sell in the marketplace by filing a set of the documents, including safety and efficacy data derived from papers that are peer-reviewed. For efficacy, RCT study papers are rigorously assessed using the methodology of Systematic Review (SR). And an overdose clinical trial in healthy Japanese is mandated for safety [10]. The sellers are therefore responsible for the safety of FFC products.

When making and designing function and health claims of the knee and other joints for foods, we should be aware of the demographic, epidemiologic, clinical, socioeconomic, regulatory, nutraceutical, etc. aspects; for example, the prevalence of osteoarthritis (OA) in the knee and other joints, characterized by elevated pain, joint discomfort, and restricted movements, is a very common chronic debilitating condition in older populations worldwide [11-13]. Generally, subjects started suffering from $\mathrm{OA}$ at around 60 years of age, which a natural consequence of aging. These findings suggest that patients with different backgrounds perceive knee OA differently [14-16]. Approximately 60\% of the Japanese adult population aged 60 years and above, suffer from radiographic knee OA, while $26 \%$ of these population suffer from symptomatic knee OA [17]. Appropriate self-care, healthy nutrition and weight control and moderate exercise are essential for subjects from OA discomfort. It is indispensable for health care professionals to discuss the mechanistic aspect of knee $\mathrm{OA}$ and discuss with the patients how to reduce the pain and progression of the diseases $[18,19]$. Moreover, subjects aged 35-65 years, who are suffering from joint pain may delay the onset of the progression of OA by modifying their lifestyle, exercise, and proper food habits [20].

Consequently, it is very crucial to understand the importance of conservative health care with proper exercise regimen, healthy nutrition, disciplined lifestyle, and suitable supplements. Multiple mechanical and stress related factors including body height, weight, knee movements and alignment, lower extremity muscle strength, knee abduction moment bone mineral density play major roles in knee pain, inflammation, and OA [21]. Non-steroidal anti-inflammatory drugs are to some extent effective for short-term duration and are widely prescribed. Novel nutraceuticals/functional foods such as 
undenatured type II collagen, hyaluronic acid, chondroitin sulfate, glucosamine hydrochloride, curcumin, omega-3 fish oil, and methylsulfonylmethane (MSM) have shown broad spectrum effectiveness in exhibiting a chondroprotective effect on knee OA [1].

In the present open-label overdose clinical study, we examined the safety of a 10-fold higher dose of the recommended daily dose of NEXT-II', which sufficiently satisfy the human overdose safety requirement for filing FFC dossier to the CAA. The overdose study is an essential part of the FFC product dossier. We designed and established 10-fold higher dose investigation based on the daily recommended dose of NEXT- $1 I^{\circ}(40 \mathrm{mg} /$ day containing $3.2 \mathrm{mg}$ undenatured type II collagen/day). In our recent RCT study over a period of 12 weeks, a daily dose of $3.2 \mathrm{mg}$ of NEXT-II capsule was found efficacious in healthy human subjects without exhibiting any adverse effects [6]. Using the minimum content of undenatured type II collagen would warrant a broader range of safety doses. We then consider a case of sellers of the FFC NEXTII products, recommending taking 1-2 capsules a day of undenatured type II collagen for commercialization, while each capsule contains the daily recommended dose of $3.2 \mathrm{mg}$. In this case, consumers possibly take 2 -fold of the recommended daily dose for a prolonged period because FFC is classified as "foods" by definition [9], allowing users to consume FFC every day. Our study results strongly supported a wide overdose range from 5fold to 10 -fold of the recommended dose, expanding the safety margin of NEXT-II products. In addition, the broad range of safety considers the excessive intake risk in the elder population in Japan.

Overall results of the open-label overdose study demonstrated that NEXT-II confirmed to be quite safe to consume a 10-fold overdose of the recommended dose over a period of 4 weeks followed by a follow-up period of 2 subsequent weeks, without NEXT-II supplementation. All parameters including physical well- being, blood biochemistry, hematology parameters, and urine tests were critically evaluated. All values were within the range of average healthy Japanese population. No significant adverse events were observed.

\section{CONCLUSIONS}

We confirmed the broad-spectrum safety of NEXT-II as determined in this open-label overdose study, supplementing a 10 -fold higher daily dose of NEXT-II [400 mg/day containing $32 \mathrm{mg}$ of undenatured type ॥ collagen/day] to 21 male and female healthy Japanese volunteers aged 20-74 over a period of 4 consecutive weeks and additional 2 weeks period of washout after terminating the supplementation. The results demonstrated no adverse effects in these subjects.

Abbreviations: FFC, foods with function claims; NEXT-II, chicken sternum cartilage powder; GMP, good manufacturing practice; FOSHU, foods for specified health uses; CAA, consumer affairs agency; SR, systematic review: QOL, quality of life; RCT, randomized clinical trial; CAA, consumer affairs agency.

Competing interests: YS, MT, MK and HM are employees of Ryusendo Co., Ltd., the study sponsor. YS, MT, MK, $\mathrm{HM}$, and $\mathrm{KM}$ were not involved in the interpretation of results and did not influence the outcomes at any stage of the clinical trial. $D B$ and $M B$ are independent consultants who reviewed the manuscript. All authors have declared that they have no other conflict of interest.

Author's contributions: All authors contributed equally and approved the version of the manuscript to be submitted.

Acknowledgements: We would like to thank everyone who cooperated with this study, the participants, Miura 
Clinic, Medical Corporation Kanonkai, Oneness support Co., Ltd., and the staff of each medical institution. We thank DB and our group members at Ryusendo Co., Ltd. for their technical support and valuable discussions.

Funding: This study was partially funded by Ryusendo Co., Ltd., Japan.

\section{REFERENCES}

1. Bagchi D, Moriyama H, Raychaudhuri SP eds. (2011) Arthritis: pathophysiology, prevention and therapeutics. Boca Raton (FL): CRC Press/Taylor \& Francis, pp. 1-577.

2. Trentham DE, Dynesius-Trentham RA, Orav EJ, Combitchi D, Lorenzo C, Sewell KL, Hafler DA, Weiner HL. Effects of oral administration of type II collagen on rheumatoid arthritis. Science. 1993; 261(5129): 1727-1730. doi: 10.1126/science. 8378772 .

3. Crowley DC, Lau FC, Sharma P, Evans M, Guthrie N, Bagchi M, Bagchi D, Dey DK, Raychaudhuri SP. Safety and efficacy of undenatured type II collagen in the treatment of osteoarthritis of the knee: a clinical trial. Int J Med Sci., 2009; 6(6) :312-321. doi: 10.7150/ijms.6.312.

4. Lugo JP, Saiyed ZM, Lau FC, Molina JPL, Pakdaman MN, Shamie AN, Udani JK. Undenatured type II collagen (UC-II') for joint support: a randomized, double-blind, placebocontrolled study in healthy volunteers. J Int Soc Sports Nutr. 2013; 10(1): 48. doi: 10.1186/1550-2783-10-48.

5. Yoshinari O, Moriyama H, Shiojima Y, Miyawaki H. Safety and efficacy of NEXT-II ${ }^{\circledR}$, a novel water-soluble, undenatured type II collagen in healthy human subjects suffering from occasional knee joint pain. Functional Foods in Health Disease. 2015; 5(7): 251-264. doi: 10.31989/ffhd.v5i7.187.

6. Shiojima Y, Takahashi M, Takahashi T, Maruyama K, Moriyama $H$, Bagchi D, Bagchi M. Efficacy and safety of Dietary Undenatured Type II Collagen on Joint and Motor Function in Healthy Volunteers: A Randomized, DoubleBlind, Placebo-Controlled, Parallel-Group Study. J Am Coll Nutr., 2022 (in press).

7. Yoshinari O, Marone PA, Moriyama H, Bagchi M, Shiojima Y. Safety and toxicological evaluation of a novel, water-soluble undenatured type II collagen. Toxicol Mech Methods. 2013; 23(7):491-499. doi: 10.3109/15376516.2013.781255

8. Yoshinari $\mathrm{O}$, Moriyama $\mathrm{H}$, Shiojima $\mathrm{Y}$. An Overview of a
Novel, Water-Soluble Undenatured Type II Collagen (NEXTII). J Am Coll Nutr. 2015; 34(3): 255-262. doi: 10.1080/07315724.2014.919541.

9. Ohama $\mathrm{H}$, Ikeda $\mathrm{H}$, Moriyama $\mathrm{H}$. Health foods and food with health claims in Japan. Toxicology. 2006; 221(1): 95-111. doi: 10.1016/j.tox.2006.01.015.

10. Bagchi D, ed. (2019) Nutraceuticals and Functional Food Regulations in the United States and around the World. $3^{\text {rd }}$ Ed., USA: Academic Press/Elsevier, pp. 1-678.

11. Chen A, Gupte C, Akhtar K, Smith P, Cobb J. The global economic cost of osteoarthritis: how the UK compares. Arthritis. 2012;2012:698709. doi: 10.1155/2012/698709

12. Cross $M$, Smith $E$, Hoy $D$, Nolte $S$, Ackerman I, Fransen $M$, Bridgett L, Williams S, Guillemin F, Hill CL, Laslett LL, Jones G, Cicuttini F, Osborne R, Vos T, Buchbinder R, Woolf A, March L. The global burden of hip and knee osteoarthritis: estimates from the global burden of disease 2010 study. Ann Rheum Dis. 2014; 73(7): 1323-1330. doi: 10.1136/annrheumdis-2013-204763.

13. Kloppenburg M, Berenbaum F. Osteoarthritis year in review 2019: epidemiology and therapy. Osteoarthritis Cartilage. 2020; 28(3): 242-248. doi: 10.1016/j.joca.2020.01.002.

14. Richardson JC, Grime JC, Ong BN. 'Keeping going': chronic joint pain in older people who describe their health as good. Ageing Soc. 2014; 34(8):1380-1396. doi: 10.1017/S0144686X13000226.

15. Sanders C, Donovan J, Dieppe P. The significance and consequences of having painful and disabled joints in older age: co-existing accounts of normal and disrupted biographies. Sociol Health III. 2002;24(2):227-253. ISSN 0141-9889, doi: 10.1111/1467-9566.00292

16. Turner AP, Barlow JH, Buszewicz M, Atkinson A, Rait G. Beliefs about the causes of osteoarthritis among primary care patients. Arthritis Rheum. 2007;57(2):267-271. Arthritis Rheum. 2007;57(2):267-271. doi: 10.1002/art.22537.

17. Muraki S, Oka H, Akune T, Mabuchi A, En-yo Y, Yoshida M, et al. Prevalence of radiographic knee osteoarthritis and its association with knee pain in the elderly of Japanese population-based cohorts: the ROAD study. Osteoarthritis Cartilage. 2009; 17(9): 1137-1143. doi: 10.1016/j.joca.2009.04.005

18. Cuperus N, Smink AJ, Bierma-Zeinstra SM, Dekker J, Schers $\mathrm{HJ}$, de Boer F, van den Ende CH, Vliet Vlieland TP. Patient reported barriers and facilitators to using a selfmanagement booklet for hip and knee osteoarthritis in 
primary care: results of a qualitative interview study. $B M C$ Fam Pract. 2013;14:181. doi: 10.1186/1471-2296-14-181.

19. Bunzli S, Taylor N, O'Brien P, Dowsey M, Wallis J, Choong P, Shield $N$. How do people communicate about knee osteoarthritis? A Discourse Analysis. Pain Med. 2021;22(5):1127-1148 doi: 10.1093/pm/pnab012.

20. MacKay C, Sale J, Badley EM, Jaglal SB, Davis AM. Qualitative study exploring the meaning of knee symptoms to adults ages 35-65 years. Arthritis Care Res. 2016;68(3):341-347. Arthritis Care Res (Hoboken) 2016; 68(3): 341-347. doi: 10.1002/acr.22664.

21. Uritani D, Ikeda A, Shironoki T, Matsubata K, Matsura Y, Fujii T, Ikeda K. Perceptions, beliefs, and needs of Japanese people with knee osteoarthritis during conservative care: a qualitative study. BMC Musculoskelet Disord. 2021; 22(1):754. doi: 10.1186/s12891-021-04641-7.2021. 